\title{
Hunting the hunter: using genetic profiling for improved management of shark attacks on humans
}

\section{CLUA ( $\nabla$ eric.clua@univ-perp.fr)}

Ecole Pratique des Hautes Etudes https://orcid.org/0000-0001-7629-2685

MEYER

University of HAwaii

LINNELL

Norvegian Institute for NAture Research

BAKSAY

CRIOBE

VIGNAUD

CRIOBE

VELY

Direction Agriculture Aménagement et Forêt

PLANES

Centre NAtional Recherche Scientifique

\section{Research Article}

Keywords: human-wildlife conflict, problem individuals, barcoding, fingerprinting, eco-responsible management, selective removal

Posted Date: May 25th, 2021

DOI: https://doi.org/10.21203/rs.3.rs-549718/v1

License: (c) (1) This work is licensed under a Creative Commons Attribution 4.0 International License.

Read Full License 
Title (max 15 words $-\mathrm{n}=14$ )

4 Hunting the hunter: using genetic profiling for improved management of shark attacks

5

6

7

\section{on humans}

Eric E. G. Clua ${ }^{1,2}$, Carl Meyer ${ }^{3}$, John D. C. Linnell ${ }^{4,5}$, Sandra Baksay, ${ }^{1,2}$ Michel Vely ${ }^{6,7}$, Thomas Vignaud ${ }^{1,2}$, Serge Planes ${ }^{1,2}$

1 PSL Université Paris: EPHE-UPVD-CNRS, USR 3278 CRIOBE, Université de Perpignan, Perpignan, France, 2 Laboratoire d'Excellence "CORAIL," Perpignan, France, 3 Hawaii Institute of Marine Biology,University of Hawaii at Manoa, P. O. Box, 1346, Kaneohe, Hawaii, USA, 4 Norwegian Institute for Nature Research, PO Box 5685 Torgard, NO-7485 Trondheim, Norway, 5 Inland Norway University of Applied Sciences, NO-2480 Koppang, Norway 6 Ministère de l'Agriculture, Direction de l'Alimentation, de l'Agriculture et de la Forêt (DAAF), 21 rue de Spring, 97150 St-Martin, France 7 Megaptera association, 23 Rue Alexandre Dumas, 75011 Paris, France.

Summary (max. $150-n=140)$

DNA evidence is routinely used to identify individual predators responsible for attacks on people and livestock in terrestrial settings. However, the use of transfer DNA techniques in aquatic environments for similar purposes is a recent development. To date, DNA barcoding has been used successfully to identify shark species depredating fish catches and biting surfboards and neoprene surfaces. In this study we demonstrate the successful DNA barcoding and fingerprinting of individual sharks from transfer DNA collected directly from the wounds of two shark bite victims. The successful use of DNA techniques to identify both species and specific individuals responsible for shark bites opens the door to selective removal of these individuals as an innovative shark bite risk management strategy.

This selective approach would be a more effective, eco-responsible, cost-effective and ethical solution for vulnerable taxa than ongoing non-selective culling campaigns. 
Recent decades have seen the adoption of DNA forensic techniques for solving wildlife poaching cases and identifying culprits in terrestrial predator attacks on humans ${ }^{1,2}$. Analysis of mitochondrial DNA (mtDNA 'barcoding') is used to identify species ${ }^{3}$, whereas analysis of nuclear DNA (nDNA 'fingerprinting') can distinguish between individuals of the same species ${ }^{4}$. Microsatellites (short tandem repeats, STRs) are the preferred nuclear markers for DNA fingerprinting because of their polymorphic and co-dominant nature, strict adherence to Mendelian inheritance and high reproducibility ${ }^{5}$. STRs have been used to solving poaching cases involving wild boar ${ }^{6}$ and Sardinian Mouflons $^{7,8}$, and to identify individual brown bears (Ursus arctos) and tigers (Panthera tigris) responsible for fatal attacks on humans ${ }^{9,10}$. The source of DNA in these cases was either hair or blood, but successful DNA fingerprinting has also been achieved using saliva left in dog bite wounds on a child in Japan ${ }^{11}$ and livestock in Italy ${ }^{12}$. In these cases it was important to identify the specific "problem individual"13,14 responsible for the attack in order to eliminate the threat.

Shark bites on humans, commonly referred to as "shark attacks", cause about ten fatalities each year ${ }^{15}$ but receive extensive sensationalized media coverage leading to distorted public perceptions of risk ${ }^{16}$. This biased perception is reinforced by the existence of chronic clusters of bites in certain areas such as northeastern Brazil (Western Central Atlantic Ocean), Reunion Island (Indian Ocean) or the coasts of Australia, New Caledonia or Hawaii (Eastern Central Pacific) $)^{17}$. Common shark bite mitigation measures include the use of nets or repellent barriers to limit contact between ocean users and sharks ${ }^{18}$, early detection of the animals by human spotters ${ }^{19}$, drones ${ }^{20}$ or telemetry ${ }^{21}$, and personal shark repellent devices ${ }^{22,23}$. However, non-selective mass shark culling campaigns are also still used despite the lack of evidence for their effectiveness. Previous studies concluding that culling campaigns improve human safety ${ }^{24,25}$ lack appropriate controls and show apparent trends that may simply reflect the natural rarity and stochasticity of fatal bites on humans. Other studies have shown culling campaigns do not reduce shark bites ${ }^{26}$. Indiscriminate culling of 174 tiger sharks and 125 bull sharks between January 2014 and November 2020 did not prevent the occurrence of six fatal bites around La Reunion Island (2,512 sq.km) during this period (an average of 1 fatality per year), compared to five fatal bites between 2010 and 2013 (an average of 1.2 fatalities per year). Recreational ocean use 

responsible for each bite. We discuss the implications of DNA profiling for shark bite mitigation.

around La Reunion Island has decreased significantly since $2014^{27}$, suggesting shark bite risk may actually have increased during the period of culling. The effectiveness and ethical appropriateness of shark culling is increasingly criticized by scientists and the general public alike $28,29,30$.

The rationale for mass shark culling is two-fold; (1) the culprit responsible for a bite incident may be among the sharks removed, and (2) reducing the density of sharks reduces shark bite risk. Reducing animal densities to mitigate problematic behaviors can be effective in cases where the majority of individuals are engaged in these behaviors, such as great cormorants (Phalacrocorax carbo sinensis) depredating fish catches ${ }^{31}$, sika deer (Cervus nippon) damaging trees ${ }^{32}$, or wild boar damaging crops ${ }^{33}$. However, shark bites on humans are atypical behavior for sharks - they are very rare events despite high levels of human ocean recreation activities around the world. It is possible that problem individuals exist in shark populations just as they do in populations of terrestrial predators ${ }^{15}$ and shark bites result from the atypical behavior of a few such individuals. Sharks that bite people may be at the extreme end of the behavioral spectrum for traits such as boldness (vs. shyness) and risk taking (vs. avoidance $)^{34}$. If problem individuals exist in shark populations then they could be selectively removed following bite incidents to prevent future incidents, as is the case in terrestrial environments with large predators ${ }^{14}$. Genetic profiling could be used to unequivocally identify both the species and the individual responsible for bite incidents. However, this would be contingent on DNA persisting in bite wounds despite the potential for seawater to wash it away. Recent studies have successfully used transfer DNA recovered from depredated fish catches $^{35}$, neoprene and surfboards ${ }^{36}$ to identify the culprit shark species. However, to date no study has identified both the shark species (via barcoding) and the individual within that species (via fingerprinting) using transfer DNA recovered directly from shark bite wounds in human flesh.

Here we demonstrate the successful use of transfer DNA recovered from the wounds of two recent shark bite victims to identify the culprit species and demonstrate that a different individual was 
Two swimmers were recently bitten by sharks in waters off St. Martin (French West-Indies) and the neighboring island of Nevis (West-Indies). Both incidents were witnessed by observers that visually identified the culprit as a tiger shark (Galeocerdo cuvier) in both cases. Medical personnel swabbed the bite wounds within a few hours of each incident. We successfully recovered shark mitochondrial DNA from these swabs and performed a barcoding analysis confirming the visual identification of a tiger shark in each case. All six swabs collected from the St Kitts-and-Nevis incident matched reference tiger shark mtDNA (4>98\% match, 2>94\% match). Five swab samples from St Martin yielded a $>98 \%$ match to Galeocerdo cuvier and one failed. The transfer DNA recovered from both victims also allowed the fingerprinting of both shark individuals based on 25 composite short tandem repeats (STR) (see S1). A comparison of the two individual genetic profiles showed that the two bites were perpetrated by two different individuals (see S2). As these were first-time analyses, it took several weeks to obtain results.

97 With preparation, the waiting time for barcoding and fingerprinting results could be reduced to an average of 36-40 hours and 5-7 days, respectively. Such delays would perfectly fit with the inclusion of DNA profiling in a short and long terms innovative strategy of shark risk management (Fig. 1). 


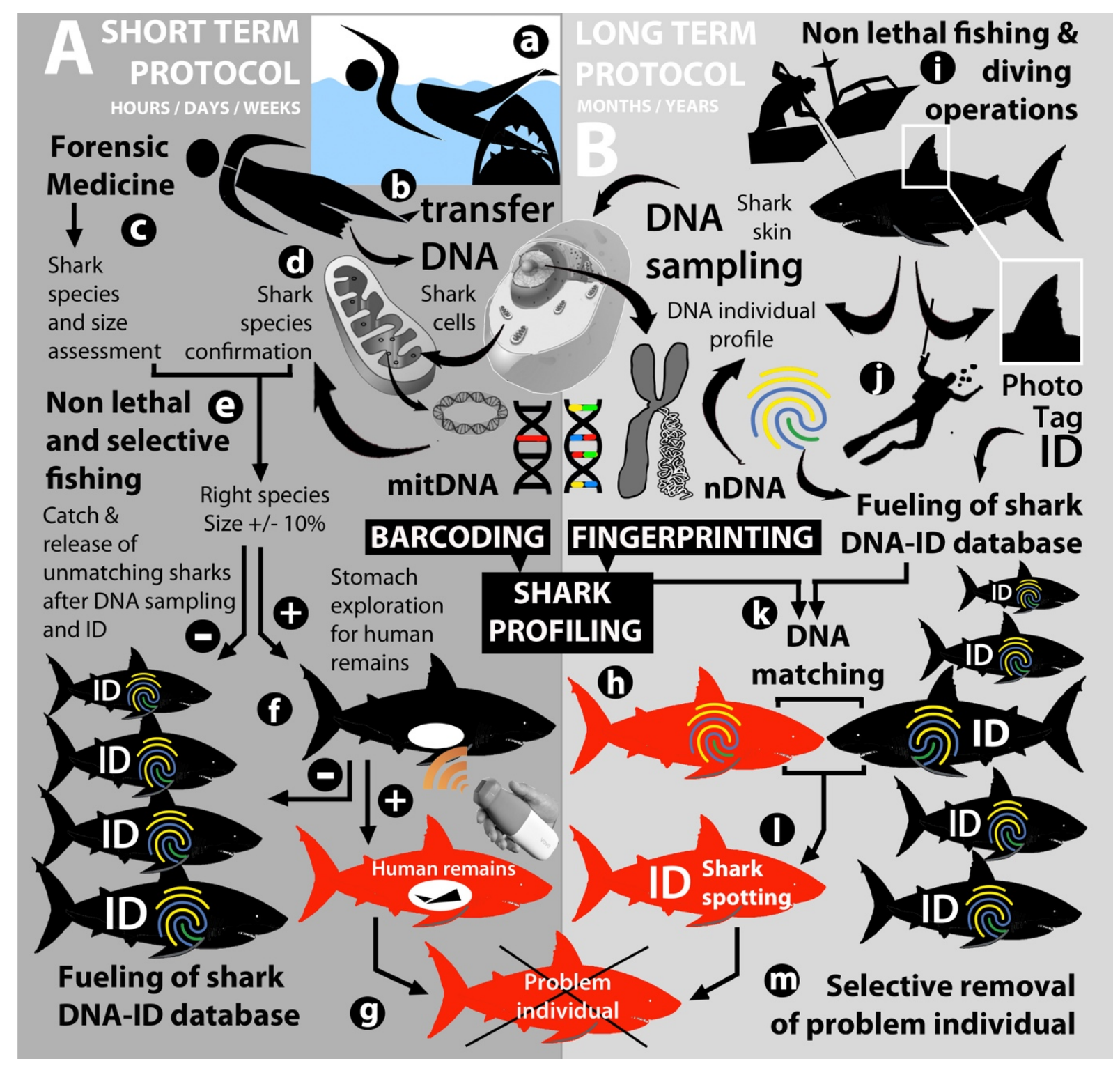

101 Fig. 1-Suggested genetic profiling strategy for selective removal of shark problem individuals. A:

102 Short-term response (hours/days) would use barcoding analysis to identify the culprit species. B:

103 Long-term response (months/years) would use genetic fingerprinting to profile the culprit individual.

104 (a) Wound-swabbing would be conducted within a few hours of a shark bite incident. (b) Forensic

105 analysis of the bite would provide an assessment of the size of the shark and the potential species.

106 (c) The culprit species would be confirmed through barcoding (delay: $36-40 \mathrm{~h}$ ) and the synthesis of

107 information would allow (d) non-lethal and selective fishing within the days after the attack. DNA

108 samples would be taken from all captured sharks and those outside the culprit size estimate (error

109 margin of $+/-20 \mathrm{~cm}$ ) would be ID tagged, photographed and released. This information would be

110 stored in a central database with the individual genetic shark profile and the means to re-identify it 
111 (photo-ID or ID tag) (e). Stomach contents of sharks matching the culprit species and size would be examined via ultrasonography or physical eversion in order to identify potential human remains. In absence of remains, the animal would be released; in presence of human remains, the animal would be culled (f). The transfer DNA from the human wounds would also allow $(\mathrm{g})$ the fingerprinting of the animal responsible for the bite. (g) Long-term measures would include routine collection of shark DNA profiles and ID tagging or photography via non-lethal fishing or diver surveys at specific monitoring sites to build a shark identification database. (h) If a culprit shark DNA profile matches a known individual in the database, that specific individual would be targeted for selective removal based on unique external characteristics (ID tag or photo).

\section{Discussion}

122 We successfully barcoded and fingerprinted shark transfer DNA samples collected by swabbing bite wounds in two separate incidents. The swabbing was performed by different individuals in each case, the samples were stored in $90^{\circ}$ alcohol and a regular freezer prior to analysis and standard protocols for DNA extraction, amplification and sequencing were applied to obtain the identification results. These results demonstrate that transfer DNA analyses could be a standard component of the forensic analysis of shark bite incidents, and would complement existing wound analyses used to estimate the size of the shark involved.

The ability to identify individual culprits provides a potential alternative to mass-culling. Non-lethal fishing could be used to try and find the individual responsible. The stomach contents of captured

132 sharks meeting the culprit species (determined via barcoding) and size criteria (within a $+/-10 \%$ error) could be non-lethally examined using a portable ultrasound unit to scan for human remains (especially bones that are more resistant to digestive juices). Our successful fingerprinting of transfer DNA from bite wounds could allow the culprit to be definitively identified and selectively removed in a similar manner to terrestrial predators that kill humans. However, the concealing nature of the ocean and wide-ranging behavior of some large shark species makes this approach more challenging than in 
terrestrial settings where large predators typically occupy well-defined home ranges, exhibit territoriality or defend carcasses and can be relatively easily found. Possible solutions to this considerable challenge include pre-emptively creating genetic reference databases of large sharks using non-lethal sampling methods (e.g. biopsy sampling of free-swimming or captured individuals).

142 Following a severe shark bite incident, the fingerprint obtained from transfer DNA could be compared to the database to identify a specific culprit that would be externally identifiable from an identification

144 tag or photo-ID. Once identified as responsible for a bite on humans and found again thanks to a 145 monitoring sites, the problem individuals could be removed (Fig. 1).

147 Existing examples of animal genetic profile databases include brown bears (Ursus arctos) $(\mathrm{n}=479)^{31}$ 148 and rhinoceros (species) $(\mathrm{n}>3,900)$. In Africa, the RhODIS ${ }^{8}$ (Rhinoceros DNA Index System) 149 database facilitated the criminal prosecution of several poachers via DNA matches between the 150 database and confiscated material ${ }^{37}$. Estimating shark population sizes is challenging and prone to 151 large error margins but existing population size estimates (e.g. 1200 bull sharks around La Reunion 152 island ${ }^{38}, 2,500-6,750$ white sharks off Eastern Australia and New Zealand ${ }^{39}$ ) illustrate the scale of 153 sampling required to create genetic profile databases. Although shark species primarily responsible for 154 biting humans may range over thousands of kilometers of ocean, they also return to specific locations 155 within their home ranges. For example, satellite-tagged bull sharks and tiger sharks have moved over 156 hundreds of kilometers in the Pacific ${ }^{40}$ and thousands of kms in the Western Atlantic ${ }^{41}$, respectively, 157 before returning to artificial provisioning sites.

159 Selective approaches have the potential to be less costly than existing culling campaigns. La Reunion 160 island had a 2018 annual budget of 2.2 million USD for shark bite risk management, including 660.000 USD for shark culling. Eighty (65 tiger and 15 bull) sharks were culled at a cost of US $\$ 8,250$ per shark, but two fatal bites still occurred in January and May $2019^{30}$. Creating a La Reunion shark

163 DNA fingerprint database (using 20-loci as for the present study) would cost of 660.000 USD based 164 on the current shark population size estimate and analysis costs of US $\$ 40-50$ per shark. The field 
165

sampling (i.e. fishing) costs would be comparable to those for the lethal culling campaign and would be spread over several years.

The substantially lower ecological impact of selective shark removal compared to mass culling should also be weighed in the cost-benefit analysis. Shark populations are already severely overfished in many locations around the world ${ }^{42}$. The removal of large numbers of top level predators reduces population genetic diversity and may result in undesirable cascade effects through marine food webs.

Similar negative impacts may result from large scale shark culling. Selective removal of a small number of sharks known to have bitten humans would bring shark bite mitigation in line with the management of terrestrial predators responsible for targeting humans.

\section{Material and methods}

\section{DNA extraction and sequencing}

DNA was extracted from the swab tips from St Martin ( $\mathrm{n}=6$ swabs) and St Kitts-and-Nevis ( $\mathrm{n}=6$ swabs) using the Gentra Puregene DNA Purification Kit (Qiagen) following manufacturer instructions. DNA extraction quality was visualized on a $2 \%$ agarose gel.

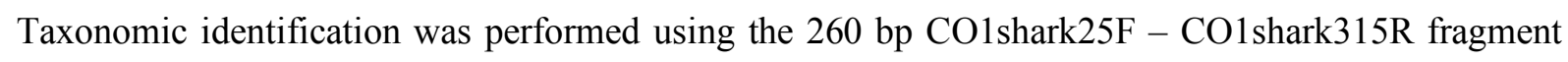
(CO1shark25F $\quad-5^{\prime} \quad$ AGCAGGTATAGTTGGAACAGCCC $\quad 3^{\prime} \quad$ and CO1shark $315 \mathrm{R} \quad-5^{\prime}$ GCTCCAGCTTCTACTCCAGC 3') (Fotedar et al., 2019). Mitochondrial sequences were amplified using Quiagen reagents kit (preciser), with $2.5 \mu 1$ Tampon TAQ 10X, $2 \mu 1 \mathrm{MgCl} 225 \mathrm{mM}, 2.5 \mu 1 \mathrm{dNTPs}$ $2 \mathrm{mM}, 0.6 \mu 1$ of each primer $(10 \mu \mathrm{M}), 0.1 \mu 1$ Taq polymerase $(5 \mathrm{u} / \mu 1)$, Ultra Pure H2O, $5 \mu 1$ QSolution, for a final volume of $25 \mu \mathrm{l}$. PCR programs consisted of an initial denaturing step at $95{ }^{\circ} \mathrm{C}$ for $3 \mathrm{~min}$., followed by 35 cycles of $95^{\circ} \mathrm{C}$ for $30 \mathrm{sec}, 62^{\circ} \mathrm{C}$ for $45 \mathrm{sec}$, and $72{ }^{\circ} \mathrm{C}$ for $30 \mathrm{sec}$, finished by $10 \mathrm{~min}$ at $72{ }^{\circ} \mathrm{C}$ and then held at $4{ }^{\circ} \mathrm{C}$ (Thermocycler Eppendorf nexus gradient). PCR products were all ran on a $2 \%$ agarose gel. PCR products were sequenced by GenoScreen (Lille - France) using an Applied Biosystem's 3730xl DNA Analyzer. 
Sequence data were analyzed with BioEdit 7.2.5 and exported to the BLAST function (fasta format)

193 from GenBank. CO1shark25F - CO1shark315R sequences were assigned allowing a best match score $194>98 \%$.

195 Genomic DNA Microsatellite markers were amplified using Type-it Microsatellite PCR kit (Qiagen, Hilden, Germany) in a final volume of $10 \mu \mathrm{L}$ including $5 \mu \mathrm{L}$ Type-it Multiplex PCR Master Mix (2X), $0.04 \mu \mathrm{L}$ of each primer ( $25 \mu \mathrm{M}$ forward and reverse primers diluted in TE $\mathrm{pH} 8$ buffer) and $1 \mu \mathrm{L}$ of DNA. PCR programs consisted of an initial denaturing step of 15 min at $95{ }^{\circ} \mathrm{C}$, followed by 40 cycles of $1 \mathrm{~min}$ at $95^{\circ} \mathrm{C}, 1 \mathrm{~min}$ at specified annealing temperature $\left(53^{\circ} \mathrm{C}, 56^{\circ}\right.$ or $58^{\circ} \mathrm{C}$ - see table 1$), 72^{\circ} \mathrm{C}$ for $1 \mathrm{~min}$, and a final elongation step at $72^{\circ} \mathrm{C}$ for $20 \mathrm{~min}$. Due to the very low genomic DNA quantity, all loci were amplified in Monoplex, PCR products were sequenced by GenoScreen (Lille - France) using an Applied Biosystems 3730 Sequencer. GeneScan 500 LIZ (Applied Biosystems) was used for accurate sizing. Allele sizes were scored and checked manually using GENEMAPPER 3.7 (Applied Biosystems).

\section{REFERENCES}

1. Alacs, E. A. et al. DNA detective: a review of molecular approaches to wildlife forensics. Forensic Sci Med Pathol. 6(3),180-194 (2010).

2. Arenas, M. et al. Forensic genetics and genomics: Much more than just a human affair. PLoS Genet 13(9), e1006960 (2017).

3. Hebert, P. D., Ratnasingham, S. \& deWaard, J. R. Barcoding animal life: cytochrome c oxidase subunit 1 divergences among closely related species. Proc Biol Sci. 270 Suppl $1: \mathrm{S} 96 \pm 9(2003)$

4. Jeffreys, A., Wilson, V. \& Thein, S. Hypervariable 'minisatellite' regions in human DNA. Nature 314, 67-73 (1985).

5. Singh, A. et al. A novel microsatellite (STR) marker for forensic identification of big cats in India. Forensic Sci Int. 141(2 \pm 3$), 143 \pm 7$ (2004).

6. Lorenzini, R. DNA forensics and the poaching of wildlife in Italy: a case study. Forensic Sci Int. 153(2 \pm 3$), 218 \pm 21(2005)$. 
7. Lorenzini, R. et al. Wildlife molecular forensics: identification of the Sardinian mouflon using

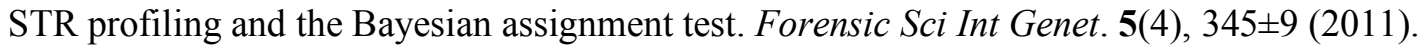

8. Barbanera, F. et al.. Conservation of endemic and threatened wildlife: molecular forensic DNA against poaching of the Cypriot mouflon (Ovis orientalis ophion, Bovidae). Forensic Sci Int Genet. 6(5), 671 \pm 5 (2012).

9. Frosch, C. et al. Case report of a fatal bear attack documented by forensic wildlife genetics. Forensic Sci Int Genet. 5(4), 342-344 (2011).

10. Lorenzini R. DNA forensics and the poaching of wildlife in Italy: a case study. Forensic Sci Int. 153(2 \pm 3$): 218 \pm 21(2005)$.

11. Tsuji, A. et al. Unusual death of a baby: a dog attack and confirmation using human and

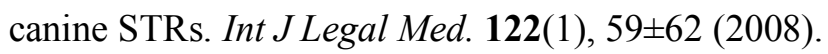

12. Caniglia, R., et al. Who is who? Identification of livestock predators using forensic genetic approaches. Forensic Sci Int Genet. 7(3), 397-404 (2013).

13. Linnell, J. D. et al. Large carnivores that kill livestock: do" problem individuals" really exist?. Wildlife Soc. Bul., 698-705 (1999).

14. Swan, G. J. et al. Ecology of problem individuals and the efficacy of selective wildlife management. Trends in Ecol \& Evol 32(7), 518-530 (2017).

15. Clua, E. E., \& Linnell, J. D. Individual shark profiling: An innovative and environmentally (2019).

16. Pepin-Neff, C., \& Wynter, T. Save the sharks: reevaluating and (re) valuing feared predators. Hum Dim of Wildlife 24(1), 87-94 (2019).

17. Chapman, B. K. \& McPhee, D. Global shark attack hotspots: Identifying underlying factors behind increased unprovoked shark bite incidence. Oc \& Coast Manag, 133, $72-84$ (2016).

18. O'Connell, C. P., et al. Testing the exclusion capabilities and durability of the Sharksafe Barrier to determine its viability as an eco-friendly alternative to current shark culling methodologies. Aqu Cons: Mar and Freshwater Ecosyst, 28(1), 252-258 (2018). 
19. Curtis, T. H. et al. Responding to the risk of White Shark attack. Global Perspectives on the Biology and Life History of the White Shark. CRC Press, 477-510 (2012).

20. Butcher, P. A. etal. Beach safety: can drones provide a platform for sighting sharks?. Wild Res 250 46(8), 701-712 (2020).

21. Meeuwig, J. J. \& Ferreira, L. C. Moving beyond lethal programs for shark hazard mitigation. An Cons, 17(4), 297-298 (2014).

22. Huveneers, C. et al. Effectiveness of five personal shark-bite deterrents for surfers. PeerJ 6, e5554 (2018).

23. Whitmarsh, S. K. et al. Effectiveness of novel fabrics to resist punctures and lacerations from 256 white shark (Carcharodon carcharias): Implications to reduce injuries from shark bites. PloS one 14(11), e0224432 (2019).

24. Dudley, S. F. J. A comparison of the shark control programs of New South Wales and Queensland (Australia) and KwaZulu-Natal (South Africa). Oc \& coast manag 34(1), 1-27

26. Wetherbee, B., Lowe, C.\& Crow, G. A review of shark control in Hawaii with recommendations for future research. Pac Sci 48, 95-115 (1994).

27. Lagabrielle, E. et al. Environmental and anthropogenic factors affecting the increasing occurrence of shark-human interactions around a fast-developing Indian Ocean island. Sci rep 8(1), 1-13 (2018).

28. Gross, M. Learning to live with sharks. Science R341 (1994).

29. Ferretti, F. et al. Reconciling predator conservation with public safety. Front in Ecol and Env 13(8), 412-417 (2015).

30. Clua, E. E. et al. Selective removal of problem individuals as an environmentally responsible approach for managing shark bites on humans. Oc \& Coast Manag 194, 105266 (2020).

31. Andreassen, R. et al. A forensic DNA profiling system for Northern European brown bears (Ursus arctos). For Sci Int: Gen 6(6), 798-809 (2012). 
32. Ueno, M., Kaji, K. \& Saitoh, T. Culling versus density effects in management of a deer population. $J$ of Wild Manag 74(7), 1472-1483 (2010).

33. Croft, S., Franzetti, B., Gill, R. \& Massei, G. Too many wild boar? Modelling fertility control and culling to reduce wild boar numbers in isolated populations. PloS one 15(9), e0238429 (2020).

34. Réale, D. et al. Integrating animal temperament within ecology and evolution. Biol rev 82(2), 291-318 (2007).

35. Fotedar, S. et al. Molecular tools for identification of shark species involved in depredation incidents in Western Australian fisheries. PloS one 14(1), e0210500 (2019).

36. Kraft, D. et al. Development and successful real-world use of a transfer DNA technique to identify culprit species in shark bite incidents. J For Sci (In press).

37. Harper, C. et al. Robust forensic matching of confiscated horns to individual poached African rhinoceros. Cur Biol 28(1), R13-R14 (2018).

38. CHARC. Etude du comportement des requins bouledogue (Carcharhinus leucas) et tigre (Galeocerdo cuvier) à La Réunion. RAPPORT SCIENTIFIQUE FINAL DU PROGRAMME CHARC (Connaissances de l'écologie et de l'HAbitat de deux espèces de Requins Côtiers sur la côte ouest de La Réunion). 130 pp. 2015.

39. Hillary, R. et al. Genetic relatedness reveals total population size of white sharks in eastern Australia and New Zealand. Sci rep 8(1), 1-9 (2018).

40. Brunnschweiler, J. M., Queiroz, N.\& Sims, D. W. Oceans apart? Short-term movements and behaviour of adult bull sharks Carcharhinus leucas in Atlantic and Pacific Oceans determined from pop-off satellite archival tagging. J fish biol 77(6), 1343-1358 (2010).

41. Hammerschlag, N. et al. Don't bite the hand that feeds: assessing ecological impacts of provisioning ecotourism on an apex marine predator. Funct Ecol 26(3), 567-576 (2012).

42. Pacoureau, N. et al. Half a century of global decline in oceanic sharks and rays. Nature 589(7843), 567-571 (2021). 
We are grateful to We are grateful to His Excellency, Mr Sébastien Lecornu, French Overseas Territories Minister, for his attentive listening, to the French authorities in Saint-Martin and SaintBarthélemy, in particular Mr Serge Gouteyron, Préfet délégué of Saint-Martin and Saint-Barthélemy and Mr Julien Marie, Director, Mr Stéphane De Carli, deputy Director and Mrs Pénélope Alric, security officer of his Cabinet for their strong support as well as Commandant Stephan Basso and $\mathrm{Mr}$ Gaël Beurton from the Compagnie de Gendarmerie of Saint-Martin, for their precious help to collect swabs on Saint Martin case, to Mrs Elisabeth Barincou and Mr Antoine Lechevalier of DEAL Territorial Unit for their important technical support, to Saint Kitts and Nevis authorities, in particular Dr Tracey Challenger, chief veterinary officer (CVO) for their precious help to collect swabs on Saint kitts and Nevis case. Dr Eric Etter, Head of the secretariat of the Caribbean Animal Health Network (CARIBVET) and his colleague Dr Nonito Pages, Head of Caribbean Research and Epidemic Intelligence Center (CRVC) in Guadeloupe, French west indies, for the process and shipping of the samples to the laboratory of CRIOBE USR3278 EPHE-CNRS-UPVD of Perpignan in France, and to Dr Véronique Bellemain, deputy Director of DAAF 971, 977, 978 for the permit to import samples from Saint-Kitts to France. The first author wishes to specifically thank his colleague at CRIOBE Anne Haguenauer for the fruitful early discussions about the potential of shark genetic shark profiling that allowed the implementation of the project. The access to the body in the human fatality case in SaintMartin was allowed under the permit ref\# P.V. $n^{\circ}$ 02351/2020 from the Cellule d'Identification Criminelle de SAINT-MARTIN 978.

\section{Author contributions}

E.C. was the Coordinator of the project, and conceived the project together with S.P., C.M., J.L. and T.V. M.V. was involved in supervising the DNA sampling, storage and transportation. S.B. conducted the barcoding and fingerprinting analysis and forensic validation under S.P. supervision. The genetic data analyses were carried out by S.P.T.V. provided overall input to the paper as external experts. E.C. drafted the paper that was improved and accepted by all co-authors.

\section{Supplementary material}

333 S1: Table S1 Genetic characterization of twenty-two microsatellite loci in tiger shark (Galeocerdo cuvier)

S2: Table S2 Fingerpriniting unmatching based on comparison of STRs from both sharks.

\section{Additional information}

Supplementary Information accompanies this paper at http://www.

Competing financial interests: The authors declare no competing financial interests. Reprints and 


\section{Figures}

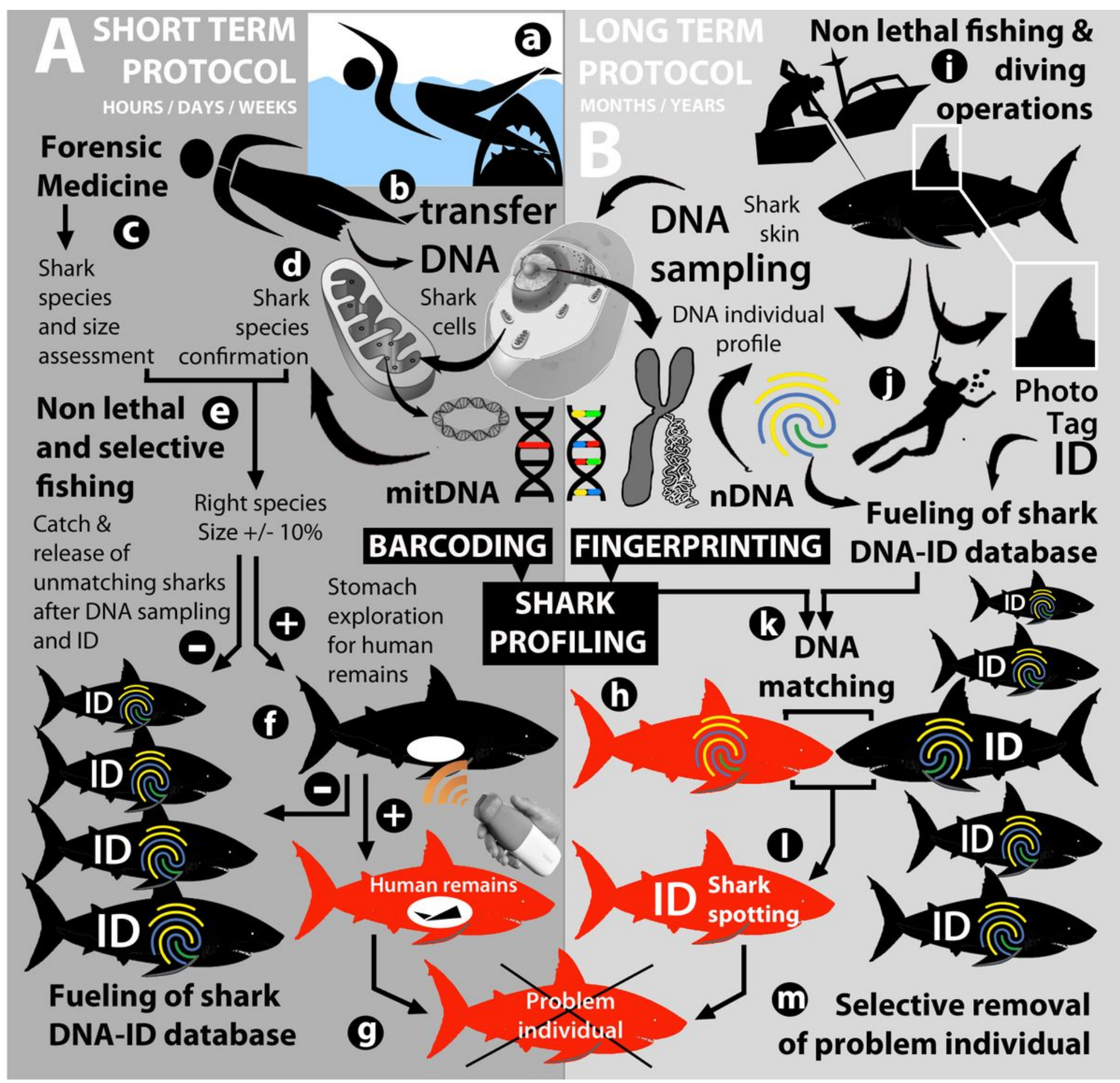

Figure 1

Suggested genetic profiling strategy for selective removal of shark problem individuals. A: Short-term response (hours/days) would use barcoding analysis to identify the culprit species. B: Long-term response (months/years) would use genetic fingerprinting to profile the culprit individual. (a) Woundswabbing would be conducted within a few hours of a shark bite incident. (b) Forensic analysis of the bite would provide an assessment of the size of the shark and the potential species. (c) The culprit 
species would be confirmed through barcoding (delay: 36-40 h) and the synthesis of information would allow (d) non-lethal and selective fishing within the days after the attack. DNA samples would be taken from all captured sharks and those outside the culprit size estimate (error margin of $+/-20 \mathrm{~cm}$ ) would be ID tagged, photographed and released. This information would be stored in a central database with the individual genetic shark profile and the means to re-identify it (photo-ID or ID tag) (e). Stomach contents of sharks matching the culprit species and size would be examined via ultrasonography or physical eversion in order to identify potential human remains. In absence of remains, the animal would be released; in presence of human remains, the animal would be culled ( $f$ ). The transfer DNA from the human wounds would also allow (g) the fingerprinting of the animal responsible for the bite. (g) Longterm measures would include routine collection of shark DNA profiles and ID tagging or photography via non-lethal fishing or diver surveys at specific monitoring sites to build a shark identification database. (h) If a culprit shark DNA profile matches a known individual in the database, that specific individual would be targeted for selective removal based on unique external characteristics (ID tag or photo).

\section{Supplementary Files}

This is a list of supplementary files associated with this preprint. Click to download.

- NCOMMS2117878S1TableS1STR.pdf

- NCOMMS2117878S2Table2fingerprintingunmatching.pdf 